\title{
Genetic Divergence Analysis in Grassspea (Lathyrus sativus L.)
}

\author{
Gangishetti Ranjithkumar $^{1 *}$, Sandip Debnath ${ }^{1}$ and Duddukur Rajasekhar ${ }^{2}$ \\ ${ }^{1}$ Department of Genetics and Plant Breeding, Palli Siksha Bhavana, Visva-Bharati, \\ Sriniketan, West Bengal, Pin-731236, India \\ ${ }^{2}$ Department of Crop Improvement, College of Post Graduate Studies in Agricultural \\ Sciences, Central Agricultural University (Imphal), Umiam, Meghalaya, India \\ *Corresponding author
}

\begin{tabular}{|c|}
\hline Keywords \\
\hline $\begin{array}{l}\text { Clusters, Crippling } \\
\text { disease, } 58 \% \\
\text { carbohydrates, } 28- \\
32 \% \text { protein, Pulses }\end{array}$ \\
\hline Article Info \\
\hline $\begin{array}{l}\text { Accepted: } \\
07 \text { November } 2019 \\
\text { Available Online: } \\
10 \text { December } 2019\end{array}$ \\
\hline
\end{tabular}

The present experiment entitled Genetic divergence analysis in Grass pea (Lathyrus sativus L.) was conducted during Rabi 2016-18 at the Agricultural Farm of Palli Siksha Bhavana (Institute of Agriculture), VisvaBharati, Sriniketan. The Experimental study was conducted with 21 genotypes. The quantitative assessment of genetic divergence was made by adopting Mahalonobish $\mathrm{D}^{2}$ statistic for yield and its contributing characters. Grouping of genotypes into different clusters was done by following Tocher's method. Studies on genetic divergence revealed that 21 genotypes are arranged in 4 clusters. Cluster I contains 18 number of genotypes. Cluster II, III, IV contains each one genotype. Highest inter cluster distance observed in the Cluster II and Cluster IV and highest intra cluster distance was observed in Cluster I.

\section{Introduction}

Grass pea (Lathyrus sativus L.) belongs to the genus Lathyrus of the family Fabaceae having chromosome number $2 n=14$. It is endowed with a number of properties spectacularly draught tolerance and a choice for rainfed farming (Palmer et al., 1989). In India, total cultivated area under pulses is 23.47 million hectares with a production of 16.47 million tonnes and productivity of $659 \mathrm{~kg} \mathrm{ha}^{-1}$, principally contributed by the states viz. Madhya Pradesh, Rajasthan, Maharashtra, Uttar Pradesh, Karnataka, Andhra Pradesh, Chhattisgarh, Orissa, Gujarat and Bihar. It has high nutritive value as its seed is known for the sole source of calories of $351 \mathrm{cal} / 100 \mathrm{~g}$ of seed with $58 \%$ carbohydrates, $28-32 \%$ protein, $0.6 \%$ fat and $3 \mathrm{~g}$ minerals per $100 \mathrm{~g}$ of seed (Aykroyd and Doughty, 1964). Despite having the "lathyrism" effect expediting crippling disease, the seed of this plant is delicious and 
contain a high amount of free $\alpha$ - homoarginin, which acts as a precursor of Lycine in higher animals. Advancement in lathyrus breeding has been proved to be successful in lowering the neurotoxin ODAP (syn BOAA) content to a safer limit. Lathyrus is safe for human consumption if the variety is having an ODAP content lower than $0.2 \%$ (Abdel Moneim and Abd-Alla, 1999). Genetic diversity refers to the total amount of genetic variation present in a germplasm or population or species or variety of genes and genotypes found in a particular crop species (Rao, 1952).

The genetic diversity is represented in terms of statistical distance is called $\mathrm{D}^{2}$ statistic. It measures the distance for a number of traits between two populations. Among several statistical methods developed for measuring diversity, $\mathrm{D}^{2}$ statistics or multivariate analysis has been extensively used for estimation of genetic diversity. The advantage with $\mathrm{D}^{2}$ statistics is that, it enables us to obtain an indication of the distances in the pdimensional shape in which samples are most distinct as also to obtain an estimate of the extent to which the sets in multiple measurements differ (Anand and Murty, 1968; Arunachalam,1981).

\section{Materials and Methods}

The present research experiment was conducted in two seasons at the Agricultural Farm of Palli Siksha Bhavana (Institute of Agriculture), Visva-Bharati, Sriniketan. meteorologically The farm is situated at $23^{\circ} 39^{\prime \prime}$ North latitude and $87^{\circ} 42^{\prime \prime}$ East longitude and at an altitude of $59 \mathrm{~m}$ above mean sea level. The experiment was conducted during Rabi 2016-17 and Rabi 2017-18 with 3 replications. Twenty one genotypes are used for the experimental study. The list of genotypes presented in the table 1. The observations were recorded in all the two seasons on the following different quantitative characters in the field. Data on various characters viz., days to flower initiation, days to $100 \%$ flowering, days to $50 \%$ pod maturity, plant height, number of primary branches, number of secondary branches, number of pods plant-1,pod length, number of seeds pod1 , days to harvesting, root length and yield were recorded on Five randomly selected competitive plants from the plot. Mahalanobis's D ${ }^{2}$ statistic (Rao, 1952) was used for estimation of genetic divergence among twenty one genotypes with respect to selected traits. Procedure suggested by Tocher (Rao, 1952) has been used to group genotypes into different clusters by treating the estimated $\mathrm{D}^{2}$ values as the square of the generalized distance.

\section{Results and Discussion}

The D2 values between any two genotypes was calculated as the sum of squares of the differences between the mean values of all the thirteen characters and used for the final grouping of the genotypes. Procedure suggested by Tocher (Rao, 1952) has been used to group 21 genotypes into four clusters by treating the estimated D2 values as the square of the generalized distance. Cluster I contains 18 genotypes where cluster II, cluster III, cluster IV contains each one genotype (Table 2).

\section{Cluster means of characters}

The cluster mean for characters studied in Lathyrus genotypes revealed considerable differences among all the clusters. From the present data, it is evident that highest cluster mean value for days to flower initiation observed in cluster IV (61.73 days) while lowest cluster mean value observed in cluster II (48.88). Cluster III (83 days) was recorded for the highest mean value for $100 \%$ flowering and cluster II (67.50) was recorded as the lowest mean value for $100 \%$ flowering. 
Cluster III (73.43) had the earliest days to $50 \%$ pod maturity while cluster IV (78.93days) had the late days to $50 \%$ pod initiation. Maximum days to harvesting observed in the cluster II (109.33 days) while minimum days observed in the cluster I (101.48 days).

Cluster mean of plant height was highest in cluster II $(32.65 \mathrm{~cm})$ and lowest in cluster III $(21.98 \mathrm{~cm})$ recorded least value. Maximum number of primary branches was recorded in cluster III (3.67) while minimum was recorded in cluster IV (2.67) and Maximum number of secondary branches was recorded in cluster III (4.67) while minimum number of secondary branches was recorded as 2.67 in cluster IV and cluster II. The cluster mean of maximum number of pod plant ${ }^{-1}$ observed in cluster II (11.61) and minimum was observed in cluster III (6.55). The cluster mean of maximum number of seed pod $^{-1}$ observed in cluster III (2.47) while minimum number of seed pod $^{-1}$ observed in cluster IV (1.37). Highest cluster mean value of pod length was observed in the cluster IV $(2.72 \mathrm{~cm})$ and lowest value observed in the cluster I $(2.60 \mathrm{~cm})$.

The highest cluster mean for root length was observed in the cluster IV $(9.20 \mathrm{~cm})$. and the lowest observed in the cluster II $(6.70 \mathrm{~cm})$. the maximum seed yield cluster mean observed in the cluster II $(17.50 \mathrm{~g})$ and minimum cluster mean value observed in the cluster IV $(12.08 \mathrm{~g})$.

\section{Average intra and inter cluster distances}

Clustering pattern on the basis of $\mathrm{D}^{2}$ analysis has been presented in Table 3. The genotypes were grouped into four non-overlapping clusters.

The average inter and intra-cluster distance in Lathyrus germplasm was presented in Table 3 The highest intra cluster distance was recorded in cluster I (17.82) followed by cluster II
(0.00), cluster III (0.00) and cluster IV (0.00) showed lowest intra cluster distance. Whereas, highest inter cluster distance was observed between cluster II and IV (142.14), which is followed by cluster II and III (114.38) and cluster I and IV (59.46) Whereas, lowest inter cluster distance was recorded in between cluster III and IV (38.94) followed by cluster I and III (41.93) and cluster I and II (46.3).

The genotypes distributed randomly to different clusters irrespective of geographical origin. The clustering pattern of these genotypes under the study suggested that geographic diversity may not be necessarily related with genetic diversity. Many genotypes/varieties received from same place have been grouped into different cluster.

\section{Genotypic distance among the genotypes}

On the basis of D-square analysis the genotypic distance between all 21 genotypes was recorded and presented in the table 4 . The highest genotypic distance was found between Velva Local and Nirmal was 1195.56 followed by Nirmal and Shiruha Local was 1147.07, Velva Local and Nowda Local was 1035.64. The lowest genotypic distance was found between Prateek and WBK-21-2-2 was 47.21 followed by WBK-9-3 and WBK-14-7 was 53.42, Prateek and Mahatewra was 59.81, Prateek and WBK-2 was 67.10. Similar findings were also reported for cluster distances by many researchers viz. Vedna et al., (2003), Yadav et al., (2005) and Kumar et al., (2006). Considerable diversity was observed for both within and between the clusters. Days to flower initiation, days to $100 \%$ flowering, days to $50 \%$ pod maturity, plant height, number of primary branches, number of secondary branches, number of pods plant ${ }^{-1}$, pod length, number of seeds pod , days to harvesting, root length and seed yield were most important. Hence selection for divergent parent based on these traits will be used for combination breeding in Lathyrus. 


\begin{tabular}{|c|c|c|c|c|c|}
\hline \multicolumn{7}{|c|}{ Table.1 Genotypes used for experimental study } \\
\hline S.no & Genotype & S.no & Genotype & S.no & Genotype \\
\hline 1 & Velva local & 8 & Mahatewra & 15 & Biol-212 \\
\hline 2 & Prateek & 9 & Nowda local & 16 & $\begin{array}{c}\text { WBK-21-2- } \\
2\end{array}$ \\
\hline 3 & Nirmal & 10 & WBK-9-3 & 17 & B-222 \\
\hline 4 & Waise & 11 & B-111 & 18 & $\begin{array}{c}\text { Shiruha } \\
\text { local }\end{array}$ \\
\hline 5 & WBK-13-1 & 12 & WBK-5 & 19 & WBK-20-5 \\
\hline 6 & WBK-11-3- & 13 & PUSA-24 & 20 & WBK-14-7 \\
\hline 7 & WBK-11-3 & 14 & WBK-2 & 21 & WBK-15-1 \\
\hline
\end{tabular}

\begin{tabular}{|c|c|c|c|}
\hline \multicolumn{4}{|c|}{ Table.2 Grouping of genotypes into various clusters } \\
\hline S.No & Cluster & $\begin{array}{c}\text { Number Of } \\
\text { Genotypes }\end{array}$ & Name Of The Genotypes \\
\hline $\mathbf{1}$ & CLUSTER I & 18 & $\begin{array}{c}\text { Prateek,Waise,WBK-13-1,WBK-11-3-1,WBK-11-3, } \\
\text { Mahatewra, Nowda local, WBK-9-3,B-111,WBK-5, } \\
\text { PUSA-24,WBK-2,Biol-212,WBK-21-2-2,B-22, } \\
\text { WBK-20-5,WBK-14-7,WBK-15-1. }\end{array}$ \\
\hline $\mathbf{2}$ & CLUSTER II & 1 & Nirmal \\
\hline $\mathbf{3}$ & $\begin{array}{c}\text { CLUSTER } \\
\text { III }\end{array}$ & 1 & Velva local \\
\hline $\mathbf{4}$ & $\begin{array}{c}\text { CLUSTER } \\
\text { IV }\end{array}$ & 1 & Shiruha local \\
\hline
\end{tabular}

Table.3

\begin{tabular}{|c|c|c|c|c|}
\hline & CLUSTER I & CLUSTER II & CLUSTER III & CLUSTER IV \\
\hline CLUSTER I & 17.82 & 42.43 & 41.93 & 59.46 \\
\hline CLUSTER II & & 00.00 & 114.48 & 142.14 \\
\hline CLUSTER III & & & 00.00 & 38.94 \\
\hline CLUSTER IV & & & & 00.00 \\
\hline
\end{tabular}


Table.4 Distance among the 21 genotypes based on values of D-square analysis (all combinations)

\begin{tabular}{|c|c|c|c|c|c|c|c|c|c|c|c|c|c|c|c|c|c|c|c|c|c|}
\hline & 1 & 2 & 3 & 4 & 5 & 6 & 7 & 8 & 9 & 10 & 11 & 12 & 13 & 14 & 15 & 16 & 17 & 18 & 19 & 20 & 21 \\
\hline 1 & 00.00 & 346.50 & 1195.56 & 571.40 & 257.15 & 500.68 & 518.92 & 327.03 & 1035.64 & 484.50 & 740.65 & 598.38 & 455.30 & 319.38 & 456.40 & 287.20 & 308.13 & 524.50 & 364.88 & 593.10 & 377.37 \\
\hline 2 & & 00.00 & 526.80 & 262.97 & 98.56 & 271.35 & 260.82 & 59.81 & 348.34 & 70.31 & 182.25 & 162.00 & 142.96 & 67.10 & 127.76 & 47.21 & 84.59 & 280.49 & 50.31 & 93.32 & 184.15 \\
\hline 3 & & & 00.00 & 193.60 & 549.94 & 334.83 & 515.17 & 704.26 & 623.05 & 674.94 & 257.75 & 315.75 & 391.02 & 606.66 & 352.21 & 594.51 & 482.76 & 1147.07 & 534.08 & 818.64 & 472.24 \\
\hline 4 & & & & 00.00 & 187.81 & 104.45 & 212.63 & 346.13 & 531.56 & 365.15 & 190.66 & 244.88 & 122.04 & 336.66 & 180.89 & 294.09 & 208.19 & 708.81 & 300.11 & 519.38 & 187.81 \\
\hline 5 & & & & & 00.00 & 166.67 & 235.46 & 127.85 & 506.12 & 192.06 & 219.19 & 153.41 & 140.87 & 80.89 & 166.68 & 105.06 & 87.78 & 484.24 & 126.35 & 226.72 & 128.83 \\
\hline 6 & & & & & & 00.00 & 95.34 & 385.72 & 349.62 & 343.18 & 153.71 & 227.13 & 81.33 & 324.22 & 207.80 & 321.18 & 129.84 & 581.68 & 295.34 & 455.36 & 245.72 \\
\hline 7 & & & & & & & 00.00 & 376.16 & 257.37 & 247.03 & 284.87 & 399.67 & 113.99 & 362.68 & 276.99 & 308.99 & 167.26 & 342.67 & 235.44 & 366.96 & 305.81 \\
\hline 8 & & & & & & & & 00.00 & 548.80 & 153.48 & 326.99 & 260.57 & 217.24 & 118.40 & 178.40 & 53.19 & 160.21 & 338.09 & 105.43 & 156.24 & 208.94 \\
\hline 9 & & & & & & & & & 00.00 & 272.23 & 228.79 & 470.94 & 274.41 & 489.97 & 454.36 & 522.28 & 315.51 & 391.59 & 367.06 & 295.68 & 606.45 \\
\hline 10 & & & & & & & & & & 00.00 & 265.43 & 327.77 & 204.39 & 167.69 & 316.01 & 139.27 & 156.32 & 188.40 & 94.95 & 53.42 & 192.56 \\
\hline 11 & & & & & & & & & & & 0.00 & 130.38 & 144.73 & 240.38 & 200.32 & 320.63 & 181.88 & 276.08 & 276.08 & 289.48 & 309.52 \\
\hline 12 & & & & & & & & & & & & 00.00 & 185.12 & 196.50 & 134.50 & 196.98 & 171.92 & 713.18 & 222.34 & 327.24 & 293.00 \\
\hline 13 & & & & & & & & & & & & & 00.00 & 230.82 & 105.01 & 181.37 & 100.96 & 419.52 & 176.37 & 297.11 & 230.82 \\
\hline 14 & & & & & & & & & & & & & & 00.00 & 176.77 & 88.08 & 121.70 & 450.78 & 88.42 & 180.49 & 199.32 \\
\hline 15 & & & & & & & & & & & & & & & 00.00 & 116.22 & 117.71 & 522.89 & \begin{tabular}{|l|}
157.69 \\
\end{tabular} & 353.63 & 323.12 \\
\hline 16 & & & & & & & & & & & & & & & & 00.00 & 98.83 & 303.78 & 88.08 & 181.90 & 178.61 \\
\hline 17 & & & & & & & & & & & & & & & & & 00.00 & 291.65 & 86.29 & 209.17 & 192.97 \\
\hline 18 & & & & & & & & & & & & & & & & & & 00.00 & 262.07 & 256.63 & 515.44 \\
\hline 19 & & & & & & & & & & & & & & & & & & & 00.00 & 152.72 & 175.64 \\
\hline 20 & & & & & & & & & & & & & & & & & & & & 00.00 & 256.63 \\
\hline 21 & & & & & & & & & & & & & & & & & & & & & 00.00 \\
\hline
\end{tabular}

Where

$\begin{array}{ll}\text { 1. Velva local } & \text { 2. Prateek }\end{array}$

3.Nirmal

4. Waise

5. WBK-13-1, 6

6. WBK-11-3-1 7.WBK-11-3

8. Mahatewra 9. Nowda local 10. WBK-9-3.

11. B-111 12. WBK-5

13. Pusa- 24

14. WBK-2

15. BIOL-212

16. WBK-21-2-2 17. B-222,

18. Shiruha local 19. WBK-20-5

20. WBK-14-7

21. WBK-15-1 
Crossing between the most divergent genotypes, viz. Velva Local $\mathrm{X}$ Nirmal, followed by Nirmal $X$ Shiruha Local and Velva Local X Nowda Local may offer a promising $F_{1}$ hybrid or otherwise be utilized to generate a segregating population with wider variability.

\section{Acknowledgement}

The authors acknowledge Mr. A.K. Manna, scientist, PORS, West Bengal for providing germplasm for conductance of this research work. Sincere acknowledgement is also there for IFAD-ICARDA project in SOUTH ASIA on "Enhancing food and nutritional security and improved livelihoods through intensification of rice-fallow system with pulse crops" running at Visva-Bharati centre for providing support to carry out the experiment.

\section{References}

Abdel-Moneim, A. Y and Abd-Alla, M. S. 1999. Feed preference by Baladi goats. Applied Animal Behavioural Science., 65 (1): 63-72.

Anand, I. J., and Murty, B. R. (1968). Genetic divergence and hybrid performance in linseed. Indian J. Genet.

Arunachalam, V. (1981). Genetic distance in plant breeding. Indian Journal of Genetics and Plant Breeding (The), 41(2), 226-236.

Aykroyd, W.R. and Doughty, J. 1964 Legumes in Human Nutrition. F.A.O. Nutritional Studies No. 19, F.A.O. Rome, pp. 67-68.

Rao, C.R. 1952. Advance Statistical Method in biometrical Research, John Wiley \& sons publishers, New York.

Palmer, V.S., Kaul, A.K and Spencer, P.S.1989. International Network for the Improvement of Lathyrus sativus and the Eradication of Lathyrism (INILSEL): A TWMRF initiative. Third World Medical Research Foundation, New York Pp. 219-223.

Vedna, K. and Prasad, K. 2003. Heterosis for seed yield and its relationship with genetic divergence in grass pea (Lathyrus sativus L.). Indian Journal of Genetics and Plant Breeding.63: 49-53.

Yadav, S.S., Phogat, D.S., Solanki, I.S. and Malik, B.P.S. 2005. Genetic divergence under two environments in lentil. Indian Journal of Pulses Research. 18: 150-152.

Kumar, R, Dhari, R. and Kumar, R. 2006. Divergence studies in pea germplasm (Pisum sativum L). National Journal of Plant Improvement. 8: 122-124.

\section{How to cite this article:}

Gangishetti Ranjithkumar, Sandip Debnath and Duddukur Rajasekhar. 2019. Genetic Divergence Analysis in Grassspea (Lathyrus sativus L.). Int.J.Curr.Microbiol.App.Sci. 8(12): 562-567. doi: https://doi.org/10.20546/ijcmas.2019.812.073 